\title{
CLINICAL AND RADIOLOGICAL COMPARISON OF SURGICAL TREATMENT METHODS IN PATIENTS WITH CERVICAL SPINAL STENOSIS
}

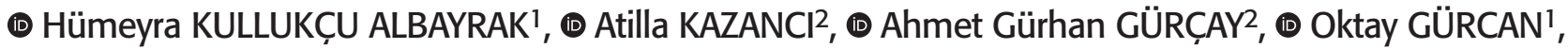 \\ (1) Mehmet Özgür ÖZATEȘ 1
}

\author{
${ }^{1}$ Ankara City Hospital, Clinic of Neurosurgery, Ankara, Turkey \\ ${ }^{2}$ Yıldırım Beyazıt University Faculty of Medicine, Depatrment of Neurosurgery, Ankara, Turkey
}

Objective: The comparison of patients who underwent different surgical procedures for cervical spinal stenosis in clinical and radiological terms with various factors.

Materials and Methods: Sixty-two patients (52 males, 10 females) were divided into groups as corpectomy (group 1), laminectomy (group 2) and laminoplasty (group 3). The patients were evaluated retrospectively considering their neurological examinations, Japanese Orthopaedic Association scores and radiological findings pre and postoperatively.

Results: The mean recovery rate was $63.2 \pm 3.7 \%$. The pre-op/post-op JOA scores of the patients were found to be $15.7 \pm 1.6 / 16.1 \pm 1.6$ in group 1 , $13.9 \pm 3.4 / 13.3 \pm 3.42$ in group 2 and, and $14.1 \pm 3.7 / 15.4 \pm 3.0$ in group 3. In terms of JOA scores the increase of the pre-op and post-op changes only in group 3 was found to be statistically significant. Statistically significant results were obtained in group 1 in terms of post-op JOA scores of the patients under the age of 60; whose sagittal cord diameter was measured as $6 \mathrm{~mm}$ or less in the pre-op cervical computed tomography (CT), with lordotic alignment of the pre-op cervical axis and who did not have T2 signal intensity increase in the pre-op magnetic resonance imaging (MRI). While evaluating group 2, no statistically significant results were obtained in any of the parameters. In group 3, it was seen that the factors including male gender, age below 60 years, sagittal cord diameter being $6 \mathrm{~mm}$ or less in pre-op cervical CT measurement, lordotic alignment of the pre-op cervical axis and no increase in T2 signal intensity in pre-op cervical MRI were seen to be statistically significant indicators for the result.

Conclusion: Early results show that better outcomes can be obtained when anterior corpectomy and fusion and open-door laminoplasty is performed in patients with under the age of 60 , have pre-op a sagittal cord diameter of $6 \mathrm{~mm}$ or less and lordotic alignment and no myelomalacia on MRI. It has been observed that better clinical and radiologic recovery can be expected in selected patients.

Keywords: Cervical spondylosis, corpectomy, lateral mass, laminoplasty

\section{INTRODUCTION}

Cervical spinal stenosis (CSS) is a progressive degenerative condition affecting the intervertebral discs and facet joints as a result of the degenerative process that develops congenitally or with advancing age. The spinal cord and the emerging roots are compressed, and patients develop radicular and myelopathic discomforts (pain). Radiologically, the incidence rate of cervical spondylosis is around $10 \%$ in people aged 25 years and younger, whereas it reaches $95 \%$ in people aged 65 years and older. The male to female ratio is $2.4: 1^{(1)}$. The diagnosis is made when the diameter of the cervical cord is 6 $\mathrm{mm}$ or less assessed using radiological imaging methods. The treatment aims at expanding the spinal stenosis and removing the compression on the neural structures through anterior or posterior surgical approaches(2). When appropriate surgical treatment is provided in a timely manner, the progression of the disease can be stopped, and the discomfort to patients can be eliminated ${ }^{(2)}$. Nowadays, the availability of diagnostic methods, improved living conditions, increased life expectancy, and diversified treatment options support the need for further studies about cervical spondylosis.

The aim of this study is to evaluate the clinical and radiological outcomes of patients who were treated with different surgical methods for CSS at the authors' clinic and to compare the efficacy of treatment methods with those reviewed in the literature. 


\section{MATERIALS AND METHODS}

Sixty-two patients who underwent surgical treatment for cervical spondylosis between 2006 and 2014 at the authors' clinic were evaluated retrospectively. Demographic, clinical and radiological data were obtained from the patient files. The subjects of the research were divided into the following groups depending on the method of operation: Group 1 had anterior corpectomy plus fusion with a cage/bone graft, group 2 had posterior decompression with laminectomy plus fusion with a lateral mass screw, and group 3 had open-door laminoplasty. Regardless of gender, patients were aged 40 to 80 years, were diagnosed with spondylotic CSS, were informed about the study, and agreed to participate. In addition, those who underwent surgery for two or more cervical intervertebral pathologies attended the follow-up examinations regularly and had cervical magnetic resonance imaging (MRI), cervical computed tomography (CT), and posteroanterior or lateral cervical direct digital radiography in the last six months were included. Followup examination appointments were scheduled to examine the patients for controlling purposes. Radiological examinations (lateral cervical direct digital radiography and non-contrastenhanced cervical $\mathrm{CT}$ ) were performed. Then, the patients were asked to fill in the Japanese Orthopaedic Association (JOA) Cervical Myelopathy Evaluation Questionnaire based on their conditions one week after the surgery and before the surgery for their conditions. The cervical lordosis angles were measured with the use of the Cobb method on the lateral cervical direct digital radiographs, and the preoperative and postoperative values were calculated. The sagittal cord diameter was calculated by measuring the anterior-posterior intradural distances with the use of the preoperative and postoperative sagittal plane cervical CT images. In this study, myelomalacia was described as the increase in signal intensity in the spinal cord, as seen in the T2-weighted sequence on the sagittal cervical MRI. The results were compared with the preoperative tests, and they were statistically analysed.

\section{Statistical Analysis}

The conformity of the data for the normal distribution was tested using the Kolmogorov-Smirnov normality analysis. The data that conformed to a normal distribution and met the parametric conditions were defined as $X \pm S D$. The differences between the two groups were determined using the Student' $\mathrm{t}$-test. The differences between the dependent groups were identified using the paired t-test, and the differences between more than two groups were analysed by a one-way ANOVA test. Identification of the different groups was tested using the Scheffe procedure. The distributions of the data that did not meet the parametric condition and did not conform to the normal distribution are provided as the median (min-max). In the comparison of three groups that did not conform to the normal distribution, the Kruskal-Wallis variance analysis was used. The different groups were identified using the Mann-Whitney $U$ test corrected by Bonferroni. Any data, including frequency, was expressed as a percentage. $P<0.05$ was considered statistically significant. SPSS 20.0 statistical program was used for the analysis.

\section{RESULTS}

The mean age of the patients included in the study was $56.6 \pm 8.3$ (43-76) years. Of 62 patients, 52 were male (83.9\%) and 10 were female (16.1\%). The follow-up period of the patients was 6-40 months (mean, $12.7 \pm 9.2$ months). When the compression level on the spinal cord was examined, 17 patients had single, nine patients had two, 10 patients had three, 16 patients had four, and 10 patients had five levels of involvement. The most frequently involved level was at the cervical segment C3-6 level, which was found in 12 patients. The mean diameter of the cord was $9.01 \pm 1.6 \mathrm{~mm}$, and the range was $6-13 \mathrm{~mm}$. The cord diameter was measured as $6 \mathrm{~mm}$ or less in $48(77.4 \%)$ patients and above $6 \mathrm{~mm}$ in 14 (22.5\%) patients. During the pre-op period, the sagittal alignment was straight in three (4.8\%) patients, lordotic in 34 (54.8\%) patients and kyphotic in 25 (40.3\%) patients. As for the post-op sagittal alignment, it was straight in nine (14.5\%) patients, lordotic in 35 (56.4\%) patients and kyphotic in 18 (29.0\%) patients. During the preop period, there was no signal change in the T2-weighted sequence in 35 (56.4\%) patients, whereas the signal intensity in the T2-weighted sequence increased in 27 (43.5\%) patients. The preoperative and postoperative parameters of all groups are given in the following tables (Tables 1, 2 and 3).

\section{Comparison of Gender}

When the pre-op and post-op JOA scores were compared concerning sex, there was a statistically significant increase in post-op JOA in males in group 3 ( $p<0.05)$.

\section{Comparison of Age}

The increases in post-op JOA values were statistically significant in group 1 and group 3 in patients under the age of 60 years $(p<0.05)$.

\section{Comparison of Compression Number}

A statistically significant difference was found among the groups in group 3 with four or more segments under compression regarding pre-op and post-op JOA scores. An increase was observed in post-op JOA scores except for group 2 in patients with four or more segments under compression, but this increase was not statistically significant except for group 3 in patients with four or more segments under compression.

\section{Comparison of Cord Diameter}

There was a statistical significance in the pre-op and post-op JOA scores in the groups undergoing compression in group 1 and group 3 patients whose cord diameter was $6 \mathrm{~mm}$ and less.

\section{Comparison of Sagittal Alignment}

The group with the lowest pre-op and post-op JOA was the kyphotic group, but this was statistically significant only in 
turkishspine

group 3. Although there was an increase in post-op JOA scores in all three groups, this increase was statistically significant only in group 1 patients with pre-op lordotic sagittal alignment and in group 3 patients with pre-op and post-op lordotic and kyphotic sagittal alignment.

\section{Comparison of Myelomalacia Presence in MRI}

In group 1, with no signal change in the pre-op T2-weighted sequence, the JOA score increased from $16.2 \pm 1.6$ to $16.8 \pm 1.3$, and in group 3 , the JOA score increased from $14.6 \pm 3.4$ to $16.2 \pm 1.9$. These results were statistically significant. Although there was an increase in post-op JOA scores in all groups in the presence of myelomalacia, these increases were not statistically significant. In addition, although there was a decrease in the post-op JOA scores in group 2, no signal change was seen in the pre-op T2-weighted sequence. This decrease in JOA scores was not statistically significant $(p>0.05)$.

\section{Comparison of Diabetes Mellitus}

The mean pre-op JOA score of the patients with Diabetes Mellitus (DM) was 14.9 \pm 2.2 in group 1,13.5 \pm 2.6 in group 2 and $13.8 \pm 1.9$ in group 3 ; whereas the mean post-op JOA score was $15.3 \pm 1.9$ in group $1,13.5 \pm 3.1$ in group 2 and $15.3 \pm 3.4$ in group 3. The mean pre-op JOA score of the patients without DM was $16.1 \pm 1.2$ in group $1,13.8 \pm 3.7$ in group 2 and $14.8 \pm 4.2$ in group 3 ; whereas the mean post-op JOA score was $16.5 \pm 1.4$ in group $1,12.8 \pm 3.6$ in group 2 and $15.7 \pm 1.5$ in group 3 . Although there was an increase in the post-op JOA scores in three groups in the presence of DM, this increase was not significant in any group $(p>0.05)$. Furthermore, there was a statistically significant difference in the post-op JOA scores in the absence of DM in group $3(p<0.05)$.

\section{Comparison of the Surgical Method}

No statistically significant difference was found among these three surgical methods regarding age and pre-op JOA ( $p>0.05)$,

Table 1. Table of parameters for the anterior corpectomy + cage/bone graft fusion group (group 1)

\begin{tabular}{|c|c|c|c|c|c|c|c|c|c|}
\hline 气 & 芩 & 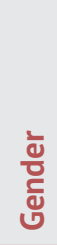 & 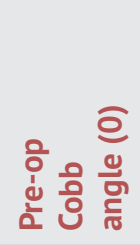 & 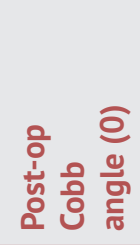 & 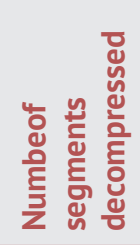 & 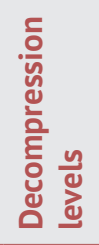 & 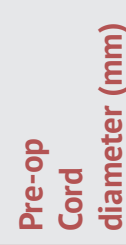 & 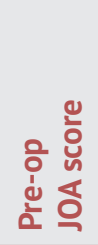 & 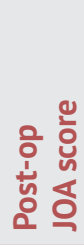 \\
\hline 1 & 62 & $M$ & 28 & 22 & 2 & $C 5-6$ & 3.1 & 16 & 15 \\
\hline 2 & 55 & $M$ & 12 & 22 & 2 & C4-5 & 4.9 & 14 & 15 \\
\hline 3 & 51 & $F$ & 16 & 12 & 1 & C5 & 5.1 & 14 & 16 \\
\hline 4 & 43 & $\mathrm{~F}$ & 10 & 30 & 2 & $C 5-6$ & 9.2 & 17 & 18 \\
\hline 5 & 51 & $M$ & 8 & 4 & 1 & C5 & 4.2 & 15 & 16 \\
\hline 6 & 55 & $M$ & 22 & 8 & 1 & $\mathrm{C} 6$ & 4.4 & 14 & 16 \\
\hline 7 & 47 & $\mathrm{~F}$ & 18 & 14 & 1 & C5 & 5.2 & 17 & 18 \\
\hline 8 & 65 & $M$ & 10 & 8 & 1 & $\mathrm{C} 6$ & 5.2 & 16 & 14 \\
\hline 9 & 58 & $M$ & 31 & 26 & 1 & $\mathrm{C} 6$ & 4.8 & 12 & 13 \\
\hline 10 & 65 & $M$ & 13 & 14 & 2 & $C 5-6$ & 7.8 & 17 & 18 \\
\hline 11 & 65 & $M$ & 16 & 10 & 1 & C5 & 7.1 & 17 & 18 \\
\hline 12 & 68 & $M$ & 12 & 10 & 2 & C4-5 & 5.6 & 13 & 13 \\
\hline 13 & 61 & $\mathrm{~F}$ & 14 & 6 & 1 & C5 & 5.1 & 16 & 17 \\
\hline 14 & 63 & $M$ & 28 & 12 & 1 & $\mathrm{C} 6$ & 6.1 & 15 & 13 \\
\hline 15 & 65 & $M$ & 24 & 22 & 2 & C5-6 & 4.2 & 15 & 16 \\
\hline 16 & 56 & $M$ & 18 & 10 & 1 & $\mathrm{C} 6$ & 6.8 & 17 & 17 \\
\hline 17 & 62 & $M$ & 12 & 8 & 1 & $\mathrm{C} 6$ & 5.6 & 17 & 17 \\
\hline 18 & 75 & $M$ & 8 & 5 & 1 & C7 & 4.8 & 16 & 17 \\
\hline 19 & 63 & $\mathrm{~F}$ & 19 & 23 & 1 & $\mathrm{C} 6$ & 5.8 & 16 & 17 \\
\hline 20 & 76 & $M$ & 15 & 28 & 2 & C5-6 & 5.9 & 14 & 15 \\
\hline 21 & 67 & $M$ & 28 & 21 & 1 & $\mathrm{C} 6$ & 6.4 & 17 & 17 \\
\hline 22 & 52 & $M$ & 9 & 4 & 1 & C6 & 5.6 & 15 & 17 \\
\hline 23 & 69 & $M$ & 25 & 23 & 1 & C5 & 6.7 & 17 & 17 \\
\hline 24 & 54 & $\mathrm{~F}$ & 4 & 1 & 1 & C6 & 6.8 & 17 & 17 \\
\hline
\end{tabular}

JOA: Japanese Orthopaedic Association, Pre-op: Pre-operation, Post-op: Post-operation, M: Male, F: Female, n: Number 
but a statistically significant difference was found in the postop JOA and the pre-op cord diameter $(p<0.05)$ (Table 4).

When the surgical methods were compared with one another, the JOA in group 3 was statistically significant $(p<0.05)$. In group 1 and group 2, a statistically significant difference was not found $(p>0.05)$ (Table 5).

\section{DISCUSSION}

Cervical spondylosis is a condition that starts at the intervertebral disc and spreads to the neighbouring bones and soft tissues as it develops. The intervertebral disc space gradually becomes smaller with the natural ageing process. Diffuse bulging and overflow of the disc are the results of this process. When hypertrophy of the ligaments (the posterior longitudinal ligament and ligamentum flavum) accompanies osteophyte formation and arthritic changes in the facet and uncovertebral joints, a circular stenosis of the spinal canal ensues. The stenosis causes compression of the medulla spinalis and nerve roots and results in myelopathy.

The surgical method to be selected in these patients is still a matter of debate. Although surgery can be performed using the anterior or posterior approach, many different results have been reported in the literature regarding the success rates of surgery using the anterior and posterior approaches. The purpose of surgery is to remove the compression that causes myelopathy and to stabilise the segmental hypermobility.
It was emphasised that many factors should be taken into consideration in the selection of the most appropriate surgical approach in cervical spondylotic myelopathy $(\mathrm{CSM})^{(3)}$. These factors include the age of the patient; lordotic, straight, or kyphotic cervical sagittal alignment; hyperintensity on MRI; the presence of more anterior or posterior compression; the number of spinal cord compression levels; and the normal range of motion and abnormal movements of the vertebra. In this study, considering the aforementioned criteria, anterior corpectomy, posterior decompression plus fusion with a lateral mass screw, and open-door laminoplasty were adapted. In a study comparing the results of the anterior and posterior approaches, Sakura et al.(4) found that both the anterior and posterior approaches resulted in similar neurological improvement. As a result of a retrospective study conducted in 629 patients with CSM, Shimomura et al. reported that no method was significantly superior to the other ${ }^{(5)}$. A recovery rate of over $80 \%$ using laminoplasty has been reported in the study by Kawai; however, in contrast, that rate in the study conducted by Morio was only $46.8 \%$. In this study, when the difference between the JOA scores was evaluated, there was a statistically significant improvement in group 3.

A corpectomy and arthrodesis are required to be performed in multilevel disc diseases such as ossification of the posterior longitudinal ligament (OPLL) and extrusion of disc fragments behind the vertebral body ${ }^{(6)}$. In their study, Fessler et al. ${ }^{(7)}$ detected some symptomatic improvement in $92 \%$ of

Table 2. Table of parameters for the posterior decompression + fusion with lateral mass screw (group 2)

\begin{tabular}{|c|c|c|c|c|c|c|c|c|c|}
\hline $\begin{array}{l}\text { 들 } \\
\text { 은 }\end{array}$ & 宅 & 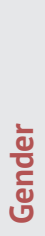 & 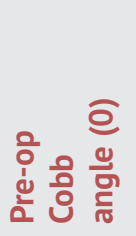 & 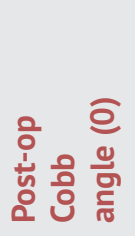 & 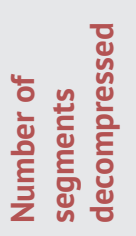 & 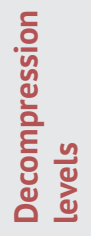 & 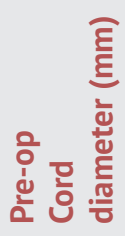 & 응 & 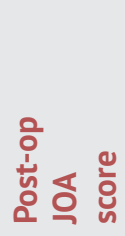 \\
\hline 25 & 67 & M & 32 & 8 & 5 & C3-7 & 4.2 & 16 & 17 \\
\hline 28 & 66 & $M$ & 35 & 18 & 4 & C3-6 & 5.4 & 16 & 16 \\
\hline 29 & 50 & $M$ & 32 & 38 & 5 & C3-7 & 5.6 & 15 & 10 \\
\hline 30 & 74 & $M$ & 0 & 15 & 5 & C3-7 & 4.5 & 17 & 13 \\
\hline 31 & 56 & $M$ & 36 & 7 & 4 & C4-7 & 6.8 & 13 & 12 \\
\hline 35 & 58 & $M$ & 24 & 10 & 5 & C3-7 & 7.2 & 14 & 1 \\
\hline 36 & 54 & $\mathrm{~F}$ & 16 & 11 & 5 & C3-7 & 6.8 & 16 & 17 \\
\hline 37 & 56 & $M$ & 26 & 20 & 4 & C3-6 & 5.1 & 17 & 17 \\
\hline 38 & 71 & $M$ & 19 & 11 & 3 & C3-5 & 4.3 & 5 & 7 \\
\hline 39 & 52 & $M$ & 4 & 6 & 5 & C3-7 & 5.4 & 13 & 15 \\
\hline 40 & 65 & $M$ & 32 & 3 & 5 & C3-7 & 4.4 & 10 & 12 \\
\hline
\end{tabular}

JOA: Japanese Orthopaedic Association, Pre-op: Pre-operation, Post-op: Post-operation, M: Male, F: Female, n: Number 
the cases and an increase in the Nurick scale score to $86 \%$ (mean: 1.24). During the mean of 49 months of the follow-up period, 37 patients, Yamazaki et al. ${ }^{(8)}$ reported improvements in neurological functions and improvements in the gait in 29 of 37 patients with OPLL who underwent corpectomy. In this study, the results are similar to those in the literature.

The development of kyphosis in the long-term postoperative period is one of the most common problems after laminectomy.
The most used method to prevent post-laminectomy kyphosis is the lateral mass screwing method developed by Roy-Camille et al.(9). Although the lateral mass screwing method is very practical, it may cause neck and shoulder pain in patients during the postoperative period because they create especially on the muscle adhesion tips and facet capsules. In their series of 13 cases who underwent posterior spinal instrumentation and were followed-up for a mean period of 25 months, Heller

Table 3. Table of parameters for the open-door laminoplasty (group 3)

\begin{tabular}{|c|c|c|c|c|c|c|c|c|c|}
\hline $\begin{array}{l}\text { 亏 } \\
\text { z }\end{array}$ & 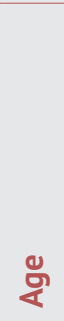 & 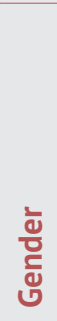 & 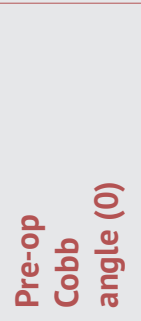 & 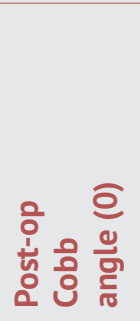 & 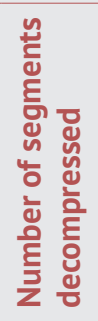 & 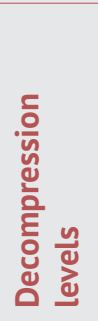 & 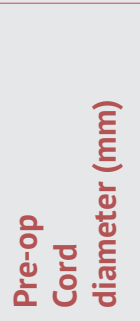 & 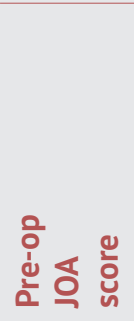 & 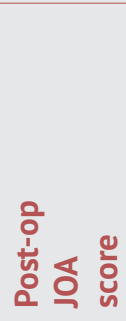 \\
\hline 41 & 64 & $M$ & 39 & 18 & 3 & C4-6 & 2.2 & 14 & 16 \\
\hline 42 & 68 & $M$ & 28 & 38 & 2 & $C 5-6$ & 5.5 & 11 & 12 \\
\hline 43 & 66 & $M$ & 22 & 13 & 4 & C3-6 & 3.3 & 15 & 15 \\
\hline 44 & 51 & $M$ & 17 & 17 & 5 & C3-7 & 3.7 & 13 & 14 \\
\hline 45 & 55 & $M$ & 33 & 33 & 4 & C4-7 & 3.4 & 12 & 14 \\
\hline 46 & 64 & $M$ & 25 & 0 & 4 & C3-6 & 4.8 & 16 & 16 \\
\hline 47 & 63 & $\mathrm{~F}$ & 33 & 30 & 4 & C3-6 & 5.1 & 17 & 17 \\
\hline 48 & 72 & $M$ & 35 & 32 & 4 & C4-7 & 2.8 & 18 & 18 \\
\hline 49 & 47 & $M$ & 5 & 2 & 4 & C3-6 & 4.1 & 18 & 18 \\
\hline 50 & 55 & $M$ & 7 & 4 & 3 & C4-6 & 5.8 & 17 & 18 \\
\hline 51 & 67 & $M$ & 34 & 24 & 3 & C4-6 & 6.1 & 7 & 17 \\
\hline 52 & 43 & $M$ & 19 & 13 & 4 & C3-6 & 4.7 & 16 & 17 \\
\hline 53 & 45 & $M$ & 23 & 15 & 3 & C5-7 & 5.2 & 17 & 18 \\
\hline 54 & 57 & $M$ & 25 & 17 & 3 & C3-5 & 3.9 & 15 & 17 \\
\hline 54 & 51 & $M$ & 31 & 26 & 4 & C3-6 & 6.7 & 13 & 15 \\
\hline 56 & 67 & $M$ & 10 & 4 & 4 & C3-6 & 5.8 & 17 & 17 \\
\hline 57 & 44 & $M$ & 18 & 16 & 2 & C4-5 & 4.1 & 17 & 17 \\
\hline 58 & 76 & $M$ & 14 & 5 & 3 & C3-5 & 4.4 & 14 & 15 \\
\hline 59 & 69 & $M$ & 16 & 11 & 4 & C3-6 & 3.9 & 16 & 16 \\
\hline 60 & 71 & $M$ & 25 & 10 & 3 & C3-5 & 4.4 & 5 & 7 \\
\hline 61 & 77 & $M$ & 26 & 30 & 4 & C3-6 & 3.4 & 7 & 8 \\
\hline 62 & 57 & $\mathrm{~F}$ & 34 & 30 & 4 & C4-7 & 5.1 & 15 & 16 \\
\hline
\end{tabular}

JOA: Japanese Orthopaedic Association, Pre-op: Pre-operation, Post-op: Post-operation, M: Male, F: Female, n: Number

Table 4. Comparison of surgical methods in terms of pre-op prognostic factors (age, pre-op and post-op JOA, pre-op cord AP diameter)

\begin{tabular}{lllll}
\hline & $\begin{array}{l}\text { Group 1 } \\
(n=24)\end{array}$ & $\begin{array}{l}\text { Group 2 } \\
(n=16)\end{array}$ & $\begin{array}{l}\text { Group 3 } \\
(n=22)\end{array}$ & $p$ \\
\hline Age & $60.3 \pm 8.3$ & $59.1 \pm 8.4$ & $60.4 \pm 10.5$ & 0.896 \\
\hline Pre-op JOA & $15.7 \pm 1.6$ & $13.9 \pm 3.4$ & $14.1 \pm 3.7$ & 0.250 \\
\hline Post-op JOA & $16.1 \pm 1.6$ & $13.3 \pm 3.4$ & $15.4 \pm 3.0$ & $0.020^{*}$ \\
\hline Pre-op cord diameter & $5.7 \pm 1.3$ & $5.5 \pm 1.0$ & $4.4 \pm 1.2$ & $0.001^{*}$ \\
\hline
\end{tabular}

JOA: Japanese Orthopaedic Association, Pre-op: Pre-operation, Post-op: Post-operation, AP: Antroposterior, n: Number 
Table 5. Comparison of surgical methods to one another basing on the pre-op and post-op JOA and the improvement ratios

\begin{tabular}{lllll} 
& $\mathrm{n}$ & Pre-op JOA & Post-op JOA & $\mathrm{p}$ \\
\hline Group 1 & 24 & $15.7 \pm 1.6$ & $16.1 \pm 1.6$ & 0.092 \\
\hline Group 2 & 16 & $13.9 \pm 3.4$ & $13.3 \pm 3.4$ & 0.720 \\
\hline Group 3 & 22 & $14.1 \pm 3.7$ & $15.4 \pm 3.0$ & $0.001^{*}$
\end{tabular}

JOA: Japanese Orthopaedic Association, Pre-op: Pre-operation, Post-op: Post-operation, AP: anteroposterior, n: Number

et al.(10) reported improvement in the Nurick classification in seven cases, no changes in four cases, and deterioration in two cases. In this study, the kyphosis angles remained the same at the preoperative and postoperative periods (mean: $5^{\circ}$ ), and the lordosis loss could not be associated with the clinic or fusion. Although there was an increase in the postoperative JOA scores as compared with the preoperative JOA scores in cases treated with laminectomy, there was no statistical significance.

Degenerative changes in the spine become more apparent during the third and fifth decades of life. In different studies, patients were divided into different age groups in order to examine the age factor. In this study, the age of 60 years was accepted as the reference age when functional degenerative changes increase. Naderi et al. ${ }^{(11)}$ found in their study that, as in many other studies, in general, age did not have an impact on the patients' postoperative neurological status, but the improvement in neurological status of the patients older than 61 years was statistically lower than those who were younger. In compliance with this finding, in this study, the postoperative neurological improvement rate of patients over 60 years old was less, which was significant. In this study, a significant difference was found between the preoperative and postoperative JOA scores of the patients over the age of 60 years in group 1 and group 3. This may result from other poor prognostic factors associated with increasing degenerative changes as age advances and low surgery tolerance of elderly patients. This finding also shows the insufficiency in the recovery of the nervous system in elderly patients.

In many studies, it is reported that the preoperative JOA scores were higher and improvement in these scores postoperatively was higher in the cases with multilevel spinal cord compression than those with single-level spinal cord compression. In this study, preoperative cervical MRI showed a statistically significant improvement in the postoperative JOA scores in patients with spinal cord compression with four levels or more in group 3.

The severity of myelopathy is known to be proportional to the anterior-posterior diameter of the spinal cord. In the studies conducted, it was reported that spinal cord diameters of $6 \mathrm{~mm}$ and less are significant regarding spinal cord compression, and $6 \mathrm{~mm}$ was accepted as a reference in this study ${ }^{(12)}$. In their study, Yamazaki et al. ${ }^{(8)}$ reported that identifying the spinal cord diameter was found to be effective in predicting the prognosis of young age patients, but it was not that effective for all age groups. In this study, in the patients with spinal cord diameters of $6 \mathrm{~mm}$ or less measured using the preoperative cervical CT in group 1 and group 3, statistically significant differences were recorded between the preoperative and postoperative JOA scores.

Flattening of the natural lordotic curve of the spine as a result of cervical instability, "S"-shaped deformity, and kyphosis are among the long-term complications of laminectomy. In the study conducted by Naderi et al. ${ }^{(11)}$; the patients were divided into two groups: normal and abnormal sagittal alignment groups. It was concluded that there was a significant postoperative neurological improvement in patients with normal sagittal alignment, while the neurological improvement in patients with abnormal sagittal alignment was not significant. In this study, the improvement in the postoperative JOA scores was statistically significant in group 1 where the sagittal alignment was lordotic. In group 3 involving the patients with lordotic and kyphotic sagittal alignments, the increase in the postoperative JOA scores was statistically significant. Lee et al.(13) reported weak preoperative and postoperative neurological conditions of the patients with CSM, who have abnormal sagittal alignments. Similarly, in this study, the mean preoperative and postoperative JOA scores of kyphotic patients were lower than those of the patients with straight and lordotic sagittal alignments. In general terms, in order to prevent postoperative kyphosis in patients operated with all the three surgical methods, being lordotic preoperatively is important.

In the compressed spine, demyelination in the lateral columns, degeneration in the posterior columns, oedema, cell loss, necrosis development, and high signal intensity in the T2weighted sequences on MRI are expressed to be caused by myelomalacia, and for the low signal intensity in T1-weighted sequence and high signal intensity in the T2-weighted sequence on MRI, cystic necrosis or secondary syringomyelia is in question. Many authors said that high signal intensity in the T2-weighted sequences on MRI correlates with neurological status ${ }^{(14)}$, whereas some authors did not express a clear correlation. Morio et al. ${ }^{(15)}$ reported that the high signal intensity in the T2weighted sequences on MRI of the spinal cord in patients with CSM may reflect the pathological changes but cannot be used to predict the prognosis ${ }^{(16)}$. They also found out that patients with improved signal intensity in the T2-weighted sequence postoperatively recovered better. In contrast to this, in their study, Sorar et al. ${ }^{(17)}$ examined the prognostic factors in patients with CSM they operated using the anterior approach. They concluded that although the decompression of the spinal cord was insufficient and the signal intensity in the T2-weighted sequence on postoperative MRI was lower compared with the 
preoperative signal intensity, the patients benefited from the anterior approach surgery and better recovery rates can be secondary to the amount of postoperative fusion development. In this study, the postoperative improvement in patients with normal signal intensity in the T2-weighted sequence on MRI in group 1 and group 3 was statistically significant compared to the postoperative improvement in those with high signal intensity in the T2-weighted sequence on MRI, which adheres to the literature. In the patients with increased signal intensity in the T2-weighted sequence on MRI, the mean preoperative and postoperative JOA scores were lower. However, this was found to be statistically significant only in group 3. In addition to this, the neurological improvement in the patients with increased signal intensity in the T2-weighted sequence on MRI during the preoperative period that decreased during the postoperative period was found to be better compared with those with a continued postoperative signal intensity increase, and that was statistically significant. This result is consistent with the literature and suggests that patients with improved signal intensity are compatible with reversible histological changes. Less improvement in signal intensity during the postoperative period results in permanent damage to the patients. However, as in other poor prognostic factors, there was a neurological improvement after the operation in the patients with increased signal intensity in the T2-weighted sequence on $\mathrm{MRI}$ in the preoperative and postoperative periods, although it was not statistically significant. Improvement in JOA scores is statistically significant only in the group without myelomalacia. $\mathrm{DM}$ is frequently seen in the general population at a rate of $2.5 \%$ in developing countries and $5-10 \%$ in developed countries. The neurological changes that develop with DM cause axon damage in the spinal cord. In this study, 17 (27.4\%) patients had DM, and the preoperative JOA scores of these patients were lower in all groups, which is consistent with the literature. Although there was an increase in the postoperative JOA scores in all three groups in the presence of DM, this increase was not significant. Moreover, in group 3, there was a statistically significant difference between the postoperative JOA scores in the absence of DM.

When we look at the literature, the likelihood of complications related to graft and/or instrument systems during corpectomy with three or more levels for decompression increases 2.5 times compared with single level corpectomy ${ }^{(18)}$. Biomechanical studies show that the following corpectomy with three levels or more, the graft and instrument systems get weaker ${ }^{(19)}$. Especially during flexion, the load on the plate and graft is reduced, and this reduces the likelihood of fusion development ${ }^{(20)}$. In the literature, anterior plate placement after graft placement is recommended as it increases the fusion rate, prevents deformity development or corrects the existing deformity, prevents the formation of a barrier in front of the graft, and prevents the graft from displacing forward. It also shares the load on the graft, preventing its collapse over the adjacent vertebra ${ }^{(20)}$. In this study, in the direction of this information, corpectomy with three or more levels was not considered as a surgical option and was not performed. Anterior plating was performed after cage/bone grafting in all the cases in this study, and plaque corpectomy cages were used in three of the patients. In only one patient, due to the posterior displacement of the fibula graft, early revision was performed during the postoperative period. In one of the patients, one of the plaque screws was identified to have loosened and then was removed one year after the operation, and, therefore, screw revision was performed.

The most common neurological complication after anterior surgical interventions is vocal cord paralysis ${ }^{(21)}$. It develops due to recurrent compression of the laryngeal nerve during surgical retraction and exploration or as a result of the occurrence of local ischemia resulting from the increased cuff pressure in the endotracheal tube. In the literature, the incidence of recurrent surgery-related laryngeal nerve damage ranges from $0.07 \%$ to $11 \%{ }^{(22)}$. Approximately $80 \%$ of patients with laryngeal nerve damage recover spontaneously within 3-4 weeks postoperatively ${ }^{(23)}$. It is important to lower the cuff of the endotracheal tube after placing the retractors and then inflate it to avoid this complication. In this study, hoarseness developed in one of the patients during the early postoperative period and spontaneously improved in the second postoperative week. In addition, Horner syndrome may develop at a rate of $0.1-1.1 \%$ in the superior ganglion cervical or the lesions of the postsynaptic fibres arising from these in the anterior approach(24). During physical assessment, miosis, ptosis, enophthalmos, anhidrosis on the face, and facial flashing are seen. In this study, one patient developed Horner syndrome, and the symptoms regressed significantly after three weeks.

In addition to these, in three of the patients who underwent anterior approach surgery, corpectomy was found to be insufficient in the policlinic follow-up and repeated examinations. This insufficiency was a result of the persistence and progression of the complications, and revision surgery was performed to complement the corpectomies at the same level. In the patients who underwent revision surgeries, the study parameters were evaluated after the first surgery.

In the patients with CSM, 0-12.9\% developed C5 radiculopathy after laminectomy, 2.5-14.9\% after laminoplasty, and 2.8$13.6 \%$ after anterior approach corpectomy ${ }^{(21)}$. The reason for the involvement of the $\mathrm{C} 5$ root is often because it has a short course and is very sensitive to traction injury after acute decompression. It has been indicated that the incidence rate of this complication is decreasing, which is thought to develop after the displacement of the spinal cord following decompression and keeping the corpectomy width small at the C4-C5 levels(25). In this study, no patient developed postoperative radiculopathy.

\section{Study Limitations}

The limitations of this study include that it is a retrospective instead of being a randomised controlled study, its relatively short follow-up periods, and its low number of patients. 


\section{CONCLUSION}

Early results show that better outcomes can be achieved when anterior approach corpectomy and fusion or open-door laminoplasty is performed in patients who are under the age of 60 years, have preoperative sagittal spinal cord diameters of $6 \mathrm{~mm}$ or less, have lordotic sagittal alignments, and have no myelomalacia on MRI. It has been observed that better clinical and radiological recovery can be expected in these patients.

\section{Ethics}

Ethics Committee Approval: Retrospective study. Informed Consent: Retrospective study.

\section{Authorship Contributions}

Concept: H.K.A., A.K., O.G., Design: H.K.A., A.K., O.G., Data Collection or Processing: H.K.A., A.G.G., M.Ö.Ö., Analysis or Interpretation: H.K.A., A.K., O.G., Literature Search: H.K.A., A.G.G., M.Ö.Ö., Writing: H.K.A.

Conflict of Interest: No conflict of interest was declared by the authors.

Financial Disclosure: The authors declared that this study received no financial support.

\section{REFERENCES}

1. Ferguson RJ, Caplan LR. Cervical spondylitic myelopathy. Neuro Clinic. 1985;3:373-82.

2. Smith GW, Robinson RA. The treatment of certain cervical spine disorders by anterior removal of the intervertebral disc and interbody fusion. J Bone Joint Surg Am. 1958;40-A:607-24.

3. Harkery HL. Approaches to multilevel cervical spondylotic myelopathy. In Controversies in Neurosurgery, Al Mefty O, Origitano TC, Harkey HL (eds). Thieme Publ 1996; 259-270.

4. Sakura $\mathrm{H}, \mathrm{Hosono} \mathrm{N}$, Mukai $\mathrm{Y}$, et a. Long term outcome of laminoplasty for cervical myelopathy due to disc herniation. A comparative study of laminoplasty and anterior spinal fusion. Spine 2005;30:756-9.

5. Shimomura $Y$, Hukuda S, Mizuno S. Experimental study of ischemic damage to the cervical spinal cord. J Neurosurg. 1968;28:565-81.

6. Ying Z, Xinwei W, Jing Z, Shengming X, Bitao L, Tao Z, et al. Cervical corpectomy with preserved posterior vertebral wall for cervical spondylotic myelopathy: a randomized control clinical study. Spine (Phila Pa 1976). 2007;32:1482-7.

7. Fessler RG, Steck JC, Giovanini MA. Anterior cervical corpectomy for cervical spondylotic myelopathy. Neurosurgery. 1998;43:257-65; discussion 265-7.

8. Yamazaki T, Yanaka K, Sato H, Uemura K, Tsukada A, Nose T. Cervical spondilotic myelopathy: surgical results and factors affect in outcome with special reference to age differences. Neurosurgery. 2003;52:1226; discussion 126.
9. Roy-Camille R, Saillant G, Berteaux D, Bisserié M. [Severe strains of the cervical spine operated on by a posterior approach (author's transl)]. Rev Chir Orthop Reperatrice Appar Mot. 1978;64:677-84.

10. Heller JG, Edwards CC 2nd, Murakami H, Rodts GE. Laminoplasty versus laminectomy and fusion for multilevel cervical myelopathy: an independent matched cohort analysis. Spine (Phila Pa 1976). 2001;26:1330-6.

11. Naderi S, Ozgen S, Pamir MN, Ozek MM, Erzen C. Cervical spondylotic myelopathy: surgical results and factors affect in prognosis. Neurosurgery. 1998;43:43-9; discussion.

12. Matsuda Y, Miyazaki K, Tada K, Yasuda A, Nakayama T, Murakami H, Matsuo M. Increased MRI signal intensity due to cervical myelopathy. Analysi of 29 surgical cases. J Neurosurg. 1991;74:887-92.

13. Lee TT, Manzano GR, Green BA: Modified open-door cervical expansive laminoplasty for spondylotic myelopathy: operative technique, outcome and predictors for gait improvement. J Neurosurg. 1997;86:64-68

14. Morio $Y$, Teshima R, Nagashima H, Nawata K, Yamasaki D, Nanjo Y. Correlation between operative outcomes of myelopathy and MRI of the spinal cord. Spine. 2001;23-6:1238-45.

15. Morio Y, Yamamoto K, Kuranobu K, Murata M, Tuda K. Does increased signal intensity of the spinal cord on Mr images due to cervical myelopathy predict prognosis? Arch Orthop Trauma Surg. 1994;113:254-9.

16. Ranawat CS, O Leary P, Pellia P. Cervical spine fusion in rheumatoid arthritis. J Bone Joint Surg. 1979;61A:1003-10.

17. Sorar M, Seçkin M, Hatipoğlu C, Budakoğlu II, Yiğikanlı K, Bavbek M, et al. Cervical compression myelopathy: is fusion the main prognostic indicator? J Neurosurgery Spine. 2007;6:531-9.

18. Boakye M, Patil CG, Jo C, Lad SP. Cervical corpectomy: complications and outcome. Neurosurgery. 2008; 63(ONS Supply 2):295-302.

19. Isomi T, Panjabi MM, Wang JL, Vaccaro AR, Garfin SR, Patel T. Stabilizing potential of anterior cervical plates in multilevel corpectomies. Spine. 1992;24:2219-23.

20. Diangelo DJ, Foley KT, Vossel KA, Rampersaud YR, Jansen TH. Anterior cervical plating reverses load transfer through multilevel corpectomies. Spine. 2000;25:783-95.

21. Bertalanffy H, Eggert HR. Complications of anterior cervical discectomy without fusion in 450 concecutive patients. Acta Neurochir (Wien). 1989;99:41-50.

22. Jung A, Schramm J, Lehnerdt K, Herberhold C. Recurrent laryngeal nerve palsy during anterior cervical spine surgery: a prospective study. J Neurosurg Spine. 2005;2:123-7.

23. Oh MC, Zhang HY, Park Jy, Kim KS. Two-level anterior cervical discectomy versus one-level corpectomy in cervical spondylotic myelopathy. Spine. 2009;34:692-6.

24. George B, Gauthier N, Lot G. Multisegmental cervical spondylothic myelopathy and radiculopathy treated by multilevel oblique corpectomies without fusion. Neurosurgery. 1999;44:81-90.

25. Galler RM, Dogan S, Filfield MS, Bozkus H, Chamberlain RH, Sonntag VKH, Crawford NR. Biomechanical comparison of instrumented multilevel cervical discectomy versus corpectomy. Spine. 2007; 23:1220-26. 